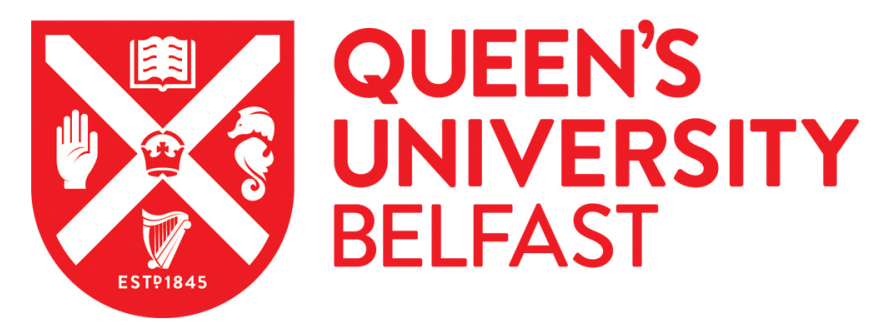

\title{
Nursing Education Challenges from Saudi Nurse Educators' and Leaders' Perspectives: A Qualitative Descriptive Study
}

Alghamdi, R., Albloushi , M., Alzahrani, E., Aldawsari, A., \& Alyousef, S. (2019). Nursing Education Challenges from Saudi Nurse Educators' and Leaders' Perspectives: A Qualitative Descriptive Study. International Journal of Nursing Education Scholarship, 16(1). https://doi.org/10.1515/ijnes-2018-0027.

Published in:

International Journal of Nursing Education Scholarship

Document Version:

Peer reviewed version

Queen's University Belfast - Research Portal:

Link to publication record in Queen's University Belfast Research Portal

Publisher rights

Copyright 2019 De Gruyter. This work is made available online in accordance with the publisher's policies. Please refer to any applicable terms of use of the publisher.

\section{General rights}

Copyright for the publications made accessible via the Queen's University Belfast Research Portal is retained by the author(s) and / or other copyright owners and it is a condition of accessing these publications that users recognise and abide by the legal requirements associated with these rights.

Take down policy

The Research Portal is Queen's institutional repository that provides access to Queen's research output. Every effort has been made to ensure that content in the Research Portal does not infringe any person's rights, or applicable UK laws. If you discover content in the Research Portal that you believe breaches copyright or violates any law, please contact openaccess@qub.ac.uk. 
NURSING EDUCATION CHALLENGES FROM SAUDI NURSE EDUCATORS' AND LEADERS'

PERSPECTIVES: A QUALITATIVE DESCRIPTIVE STUDY

${ }^{1}$ Reem Alghamdi BSN, RN, MSc, PhD candidate, School of Nursing and Midwifery, Queen's University Belfast, Belfast, Northern Ireland.

Email: ralghamdi04@qub.ac.uk

${ }^{2}$ Monirah Albloushi RN, MSN, PhD, Assistant professor, College of Nursing, King Saud University, Saudi Arabia (Corresponding author)

Email: $\underline{\text { moa687@mail.usask.ca }}$

${ }^{3}$ Aisha Aldawsari, RN, MSc, PhD candidate, University of Western Ontario, Canada Email: aaldawsa@gmail.com

${ }^{4}$ Ebtesam Alzahrani, RN, Teaching Assistant, College of Nursing, King Saud University, Saudi Arabia

Email: ealzahrani@,ksu.edu.sa

${ }^{5}$ Siham Al Yousef, RN, MSN, PhD, Assistant professor, College of Nursing, King Saud University, Saudi Arabia

Email: smansour@ksu.edu.sa 


\begin{abstract}
Aim: To explore the challenges in nursing education in Saudi Arabia from nurse educators' and leaders' perspectives.

Background: Saudi Arabia considerably lacks Saudi nurses and most nurses in Saudi healthcare facilities are expatriates with diverse academic, cultural, and linguistic backgrounds. The perception regarding nurses' profession and their low status in Saudi Arabia affect the nursing profession negatively, leading to staff insufficiency. Understanding the difficulties of the nursing profession could help intervene accordingly, in encouraging students to pursue a career in nursing.
\end{abstract}

Methods: An exploratory qualitative method was used. Three Saudi nursing educators and four leaders were interviewed. They were recruited through purposive sampling. The interviews were transcribed verbatim and data were analyzed using thematic analysis.

Findings: Participants indicated that nursing education in Saudi Arabia is facing multiple challenges requiring serious attention from Saudi leaders. The challenges were divided to four themes and different categories; cultural challenges, educational challenges, organizational challenges (weak nursing authority, lack of acknowledgement for Saudi nurses), and work challenges (poor working environment, language barrier).

Discussion: The challenges that face nursing education in Saudi Arabia were mainly at three levels: management, system, and social. These challenges were the reasons for Saudi nurses to leave the profession.

Conclusion: This study revealed some of the challenges facing nursing education in Saudi Arabia. These challenges are not unique to Saudi Arabia but knowing about these challenges will help nurse educators and leaders to improve nursing programs, enhance students' clinical experiences, and promote nursing profession in Saudi Arabia. 


\section{Introduction}

One of the global challenges facing the nursing profession is staff shortages. Saudi Arabia has experienced a considerable shortage of Saudi nurses and most nurses that work in Saudi healthcare facilities are expatriates originating from diverse academic, cultural, and linguistic settings (Aboshaiqah, 2016; Almalki, FitzGerald, \& Clark, 2011). Aboul-Enein (2002) explains that the different languages and cultural backgrounds of foreign nurses caused undesirable effects on the quality of nursing offered to Saudi patients.

To solve the staff shortage, the number of nursing programs was increased. However, Saudi nursing professionals and leaders need to address the distinct problems that face Saudi nursing education. For example, most Saudis do not consider nursing as a viable career due to its perceived nature of compelling women to work with male counterparts for long hours (ElSanabary, 2003), the challenges associated with women nursing male patients (Al-Hazmi \& Windsor, 2013), and female nurses having to work away from their families and homes (Gazzaz, 2009).

\section{Background}

One of the major reasons for the shortage of nurses in Saudi Arabia is society's negative perspective towards the profession (Al-Kandari \& Lew, 2005). This negative perception towards nursing has a ripple effect worldwide, thereby affecting an individual's decision to choose nursing as a career (Ten Hoeve, Jansen, \& Roodbol, 2013). The nursing image is related to the public's view of the nursing profession, the professional distinction of nurses, nurses' view of the public image, and the perception created by the mainstream media about nursing (RezaeiAdaryani, Salsali, \& Mohammadi, 2012). 
Many researchers have found the perspective of the nursing profession, social factors, and cultural challenges as the critical factors affecting the decision of Saudi Arabian citizens to join the nursing profession. For instance, Al-Omar (2003) analyzed the factors that deterred secondary school students from considering nursing as a profession. One of the factors was family disapproval; therefore, we infer that many Saudi families do not perceive nursing as the optimal profession for their female members. Mahran and Al Nagshabandi (2012) examined the effect of public perception of nursing on the decision-making of female nursing students regarding pursuing a career in nursing. They found that $87.8 \%$ of the Saudi people interviewed did not prefer the option of the nursing profession for their family members.

Another challenge facing Saudi nurses is inadequate education and practical readiness for working in healthcare facilities. Alboliteeh (2015) found that Saudi nurses are considering quitting the nursing profession due to poor working conditions and negative perception of the nursing image. Saudi nursing students face diverse problems during their coursework and practical lessons. The most significant and outstanding problems observed were inadequate professional proficiency and skills, and a gap in theory and practice in the nursing profession (Sharif \& Masoumi, 2005). Further, Mutair (2015) found that inadequate proficiency and skill in clinical preparedness was caused by insufficiency of qualified nursing instructors. The ones who were currently working had zero or limited skills in training nurses. Clinical educators also faced numerous challenges such as insufficient teaching skills, poor communication skills, inability to influence students positively, and inadequate preparation (Mutair, 2015). Other factors contributing to the insufficiency of Saudi nurses are Saudi socio-cultural norms and substandard working conditions. 
Further, according to Aldawsari, Babenko-Mould, and Andrusyszyn (2016), there has been a sharp increase in new nursing education programs. These programs required teachers, and many of the graduate nurses who applied for teaching positions did not have prior experience as a staff nurse or a nursing clinical teacher. Therefore, not only do the teachers in nursing programs lack experience as nurses in the field, but it seems many have not had any teaching experience as nurses at all, not even as a clinical teacher in the field.

This paper aims to explore the challenges that face nursing education from the perspectives of nursing educators and leaders. To the extent of our knowledge, this is the first qualitative descriptive study about these challenges in Saudi Arabia. The limitation of the existing nursing profession challenges studies, it is clear that the perception of the nursing profession and the low status of nurses in Saudi Arabia are negatively affecting the nursing profession, thus leading staff shortages. However, of note, most of the existing literature is outdated and focused on the perceptions of Saudi nursing trainees or students. The literature on the setbacks facing the nursing profession and education from the perspectives of the teaching personnel and administration in Saudi nursing schools/facilities were not available.

\section{Methods}

\section{Design}

In this study, an exploratory qualitative methodology was utilized. The goal of using this methodology was to explore the challenges facing education in the Saudi nursing sector from the perspectives of three leaders and four educators. Commonly, the qualitative descriptive research design is used to investigate nursing and other healthcare related problems (Kim, Sefcik, \& Bradway, 2017). This design is descriptive in nature and it's useful for exploring a poorly understood phenomenon by gaining insight from participants. The qualitative descriptive 
research allows researchers to conduct the research in a natural state, not driven by a theory or a conceptual framework (Kim, Sefcik, \& Bradway, 2017). Participants are recruited through purposive sampling because it provides a rich and more variation description of the problem. In descriptive qualitative research, the data is collected by using a semi-structured interview guide and analyzed by using thematic analysis.

\section{Participants and setting}

This study was conducted with Saudi female nurse educators and leaders who work in diverse teaching and leadership positions in Saudi Arabia. A purposive sampling strategy was used to recruit Saudi nursing educators and leaders who were interested in participating and sharing their experiences. Participants who are Saudi nurse educators and leaders with a minimum of five-year experience and have a $\mathrm{PhD}$ or master's degree were eligible for recruitment. However, participants who are teaching assistants; nursing students; have less than five years of experience; and did not finish their $\mathrm{PhD}$ or master's degree were excluded. Data saturation was reached with three nurse educators and four leaders from diverse nursing colleges and healthcare settings in Saudi Arabia.

\section{Data collection}

In-depth semi-structured interviews were conducted for one hour with seven participants includes three leaders and four educators. An interview guide consisting of seven open-ended questions was used to collect the data; participants were provided with the interview questions in both English and Arabic (Table 1). Each interview was audiotaped and transcribed verbatim by MA. Some participants preferred to conduct the interviews in Arabic because they felt more comfortable and confident speaking and expressing themselves in Arabic. Therefore, these 
transcripts were translated by an independent professional translator to ensure conceptual and semantic equivalence.

Table 1. Interview Guide

\begin{tabular}{ll}
\hline No. & \\
\hline 1 & What is your level of education? \\
2 & Where did you study Nursing? \\
3 & Did you work as a staff nurse in the hospital? If yes, for how long? \\
4 & What are the challenges that you faced when you worked as a staff nurse? \\
5 & How do you see the Nursing profession in Saudi Arabia? \\
6 & What are the challenges that face the Nursing profession in Saudi Arabia? \\
7 & What are the challenges that face Nursing education in Saudi Arabia? \\
\hline
\end{tabular}

\section{Ethical considerations}

Ethical approval was obtained from the ethics committee of the College of Nursing at King Saud University in 2017. At the beginning of each interview, written informed consent was obtained from each participant and the participants were informed that their participation was voluntary, that they could withdraw from the study at any time, and that they could choose to not answer any question.

\section{Data analyses}

Data were analyzed using thematic analysis (Braun \& Clarke, 2006). According to Guest, MacQueen, and Namey (2011), applied thematic analysis begins with generating initial codesfinding interesting features in the data and systematically coding it throughout the data set. After the data had been coded, codes were collated into potential themes by RA. The themes were then reviewed, named, and compiled into the final report by RA and MA. This was followed by an indepth analysis of the interview material, with the main guiding question being, "What challenges face nursing education in Saudi Arabia?" 


\section{Rigor}

To establish the trustworthiness and rigor of the study, the credibility, dependability, confirmability, and transferability of the findings must be determined (Lincoln \& Guba, 1985). Participants were asked for clarification during interviews to ensure their responses were completely understood. The first and second authors reviewed the data to confirm the emerging themes and ideas. To maintain dependability, the transcripts were reviewed to avoid mistakes. Coding categories were checked, compared, and verified by the first and second authors (Braun \& Clarke, 2006). Regular follow-up and comparison of codes and themes were conducted. Data were collected from educators and leaders who were working in diverse sectors and had diverse educational backgrounds. Transferability was addressed by providing rich and detailed descriptions of the research contexts and by using the data to describe several aspects of the phenomenon under investigation. By using semi-structured interviews and informal discussion, the researchers developed a comprehensive understanding of the phenomenon (Qu \& Dumay, 2011).

\section{Results}

The challenges were divided into four themes with distinct categories displayed in Figure 1. These were: cultural challenges, educational challenges, organizational challenges (i.e., weak nursing authority, lack of acknowledgement), and work challenges (i.e., poor working environment, language barriers). These themes were interrelated describing the nursing education challenges in Saudi Arabia.

Figure 1. Nursing education challenges themes and sub-themes. 


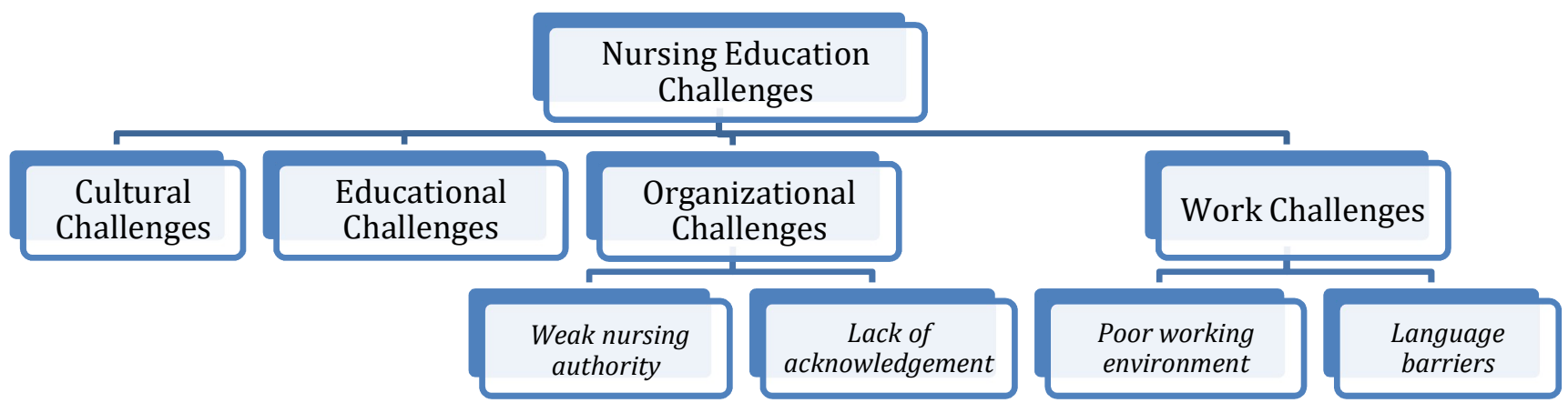

\section{Cultural challenges}

The public image of nurses in Saudi Arabia is negative. There are strong cultural traditions that restrict women from participating in paid occupations away from their homes. Therefore, women who belong to the lowest social class are the ones who seek to become nurses (Gazzaz, 2009). Analysis of the interviews revealed that there is social pressure that is linked to working in an environment that is socially unacceptable, due to cross-gender interactions. Working for long night hours was also rejected socially.

“...they [the family] were not happy about it; they were not happy at all, especially my mum." (Participant \#1)

“...after switching from medicine to nursing, it was quite traumatizing for them [my family]." (Participant \#2)

"I was interested in studying nursing; however, I was afraid of the nursing image in the community.” (Participant \#3)

“...it was very hard, very unwelcoming at the family level.” (Participant \#4)

Society looks at nurses with suspicion and some disrespect such that women fear to join the profession. Nurses are viewed as individuals who aid doctors and unless one receives positive reinforcement from family and friends, most people will not join the nursing profession. 
"We need government support in building incentives and, as I mentioned, instill a positive nursing image in the minds of the public_as individuals working in a national project, including in local campaigns for nursing services...” (Participant \#4)

Most participants agreed that motivation and appreciation by various institutions were considered a support system. Sources of support help reduce burnout and stress, which fosters job satisfaction and retention.

\section{Educational challenges}

The nursing faculty in Saudi Arabia is weak, which has led to poor educational outcomes. In some cases, the head of the nursing faculty is not a professional in the field.

“...the head of nursing has a non-nursing background; so, he does not understand the essence of nursing...” (Participant \#6)

For instance, in cases of curriculum change, those in charge just make subject changes, rather than create the curriculum to match healthcare system developments.

"They just were juggling the subjects from one area to another but not actually reinventing the curriculum..." (Participant \#6)

When referring to nursing education, the participants commented on the lack of expertise among teaching staff. Some commented on the teachers' lack of clinical experience and language and cultural barriers while others mentioning that most of the learning was textbook-oriented rather than clinically oriented.

“...professors who are teaching our nursing students have a major language barrier, a cultural barrier, and a major lack of clinical experience and, at the end of the day, nursing is all about working with patients and if those who are teaching don 't have the 
skill, how are you going to give it basically to your students? I think this is where the major gap is.” (Participant \#2)

"Because of a lack of clinical training, lack of education, (and) lack of resources that need to be available for nursing students, we are not graduating the competent nurses we need." (Participant \#1)

According to the interviews, not only is the curriculum based mostly on textbooks rather than clinical labs or field practice, but also the teachers themselves have often been out of the field for many years, detached from hands-on daily nursing work. The outcome is that they cannot, or at least do not, provide tips or information that does not appear in textbooks. It seems from the interviews that nursing education in Saudi Arabia lacks clinical emphasis and there is no added value to learning from teachers since they do not share their experience and do not provide information that is beyond the realm of technical data or procedures. Some participants also mentioned that graduate nurses have little confidence and lack of essential nursing skills, which may be a direct result of the lack of clinical training or teacher expertise.

"Because of the education, it means you are graduating as nurses who are not confident, who are not prepared, (and) who are not skillful or competent to practice nursing." (Participant \#5)

Regardless of how it was described, the participants felt that teachers fail to provide an essential aspect of nursing education. This makes it difficult for the faculty to improve because they do not understand the areas where change is needed for improving nursing education.

\section{Organizational challenges}

\section{Weak nursing authority}


The first sub-theme was identified under the organizational challenges was a weak nursing authority as participant \# 6 described. In Saudi Arabia, nurses do not have an independent nursing organization or a council to regulate their practice or protect their rights. The Saudi Commission for Health Specialties has not yet designated a scope of nursing practice or determined nurses' role legitimacy. Moreover, the nursing profession legislation is led by individuals from non-nursing backgrounds who are mostly doctors.

"Saudi Health Council is available; but, it is headed by physicians who do not understand regulation. They think having registration and licensure is regulation; but, this is not a regulation; this is part of it (one item)." (Participant \#6) Most of the nursing workforce is international and they hold leadership positions, leaving Saudi nurses feeling ignored. The decisions are made by an individual who is from either a non-nursing background or not a Saudi citizen.

“...decisions are made because we are isolated there, and we are not involved; so, somebody else is making the decision for nurses...most of those who are in key positions in hospitals are not Saudis. I am not saying they are bad or good; but, what I am saying (is) they did not give a chance to Saudi nurses to show their qualifications." (Participant \#1)

“We do not have nursing leaders to support the profession...” (Participant \#7) According to the participants who acknowledged that the nursing profession in Saudi Arabia needs reinforcement, there is a need for the development of personnel policies, regulations, and benefits that are comparable to the ones in other sectors, such as business, along with providing nursing profession advancement opportunities and proper workforce management.

\section{Lack of acknowledgement}


The second subtheme identified in the interviews was the issue of nursing as a profession. According to the participants, nursing is not necessarily fully established as a profession in Saudi Arabia.

"All healthcare professions in Saudi Arabia have successfully established their professional groups, or scientific societies, except nursing." (Participant \#4) Additionally, even if nursing is perceived as a legitimate profession, nurses are more often treated as inferior to other medical professionals, such as doctors.

"If we rank these five, \#1 is physicians, \#2 is dentists, \#3 pharmacists, \#4 allied health science specialists, and \#5 nursing comes at the end." (Participant \#6) "Anyone who is wearing a lab coat is a doctor; if she is good, she is a doctor, and if she is bad, she is a nurse. They cannot differentiate between nursing and nonnursing. " (Participant \#7)

Related to this issue, some participants mentioned that there is no acknowledgement for pursuing a nursing career, which by itself may also contribute to the poor reputation of nursing. “...nursing is a profession; but, we did not receive the recognition that we deserve." (Participant \#1)

Another one suggested government support for the Saudi nursing profession to be recognized in the community:

"We need an evident government support at the public level; so, nursing becomes visible and Saudi nurses receive recognition for their work ...” (Participant \#4)

\section{Work challenges}

\section{Poor working environment}


Poor working conditions are issues that are linked to factors such as rotating shifts, long working hours, and interactions between sexes. Given the shortage of nurses in Saudi Arabia, nurses find themselves working longer hours and they must care for many patients.

"I think (a) long shift is another issue (in this culture). For a very family oriented female to be out of the house for 12 hours when she is working as (a) bedside nurse might actually be a point of discouragement..." (Participant \#2)

“The nurses' working hours differ from the doctors' working hours. The doctors work for 8 hours while the nurses work for 12 hours. You can see why the doctors are more active in the symposiums than the nurses..." (Participant \#5)

Certainly, this deters many from pursuing nursing as a career, especially female students. The increased workload is also associated with low pay and minimal or no financial incentives. Nurses feel less appreciated and recognized, which further frustrates them, leading to a lack of work satisfaction and poor retention.

\section{Language barriers}

Language barriers are the second sub-theme for Work challenges. The type of communication is key for nursing care provisions. Most patients and their families in Saudi Arabia speak Arabic; however, most care providers speak English. Many expatriate nurses have English as their second language and are not competent in Arabic (Almutairi, 2015).

"...to sustain a profession in the clinical area one of them is also the language barrier...” (Participant \#4)

Not only did non-Arabic speaking nurses find it difficult to communicate with patients, but Saudi nurses also had trouble communicating with patients and their families due to cultural differences. 
“...the first spoken language is English in the hospital. However, I think in our curriculum, we need to add how to communicate with our patients in Arabic. I personally find it very difficult and I was never reluctant to use my own language to explain things simply in the Arabic language..." (Participant \#2)

There is a need for nurses in Saudi Arabia to communicate in the Arabic language when communicating with their patients, which may improve patients' and their families' satisfaction, thereby improving nursing care outcomes.

\section{Discussion}

A thematic analysis of seven nursing educators' and leaders' work experiences was utilized to elucidate the challenges facing nursing education in Saudi Arabia. Four overarching were revealed: cultural challenges, educational challenges, organizational challenges, and work challenges. These four themes are intertwined, as each theme builds on the other and adds another layer of complexity.

Questions regarding the professional nature of nursing are affected by the state of nursing education and the main characteristics of nursing education staff in academia (Melnyk, Gallagher-Ford, Long, \& Fineout-Overholt, 2014). Nursing as an organized and acknowledged vocation was established in the 19th century; however, the nursing practice has been around for centuries. At first, nurses were mainly educated through an "apprenticeship," in which they were taught by a senior nurse in the field (Chan, 2013). This method created significant gaps in knowledge and skills since the teaching process was not regulated or controlled. Moreover, from the viewpoint of hospitals and healthcare facilities, it was not cost-effective, and therefore the apprenticeship model was changed in the middle of the 20th century to a vocational training 
curriculum, including theoretical studies and clinical placement (Foronda, Gattamorta, Snowden, \& Bauman, 2014).

It seems from the interviews with nurses in this study that current clinical placement is either insufficient or non-existent. Nevertheless, they did stress the lack of clinical knowledge and training among graduate nurses, as well as a sense that teaching staff do not share enough of their clinical experience. Some attributed this to the fact that nurses teaching in academia are usually detached from daily nursing work. This discrepancy between the field and academia has been noted in the academic literature regarding nursing education. For instance, (Saifan, AbuRuz, \& Masa'deh, 2015) noted that while the last 30 years have seen a shift in nursing education from the hospital to universities, this shift may have created a gap in knowledge and skills between what is taught in the classroom and the actual requirements and experiences in the clinical practice. The researchers conducted a qualitative analysis based on interviews with nursing students in Jordan, finding that many felt that clinical instructors lacked sufficient qualification, which contributed to the gap in knowledge and skill. This sentiment is consistent with that presented in the current study.

The lack of clinical practice and qualification among nursing educators seems to be a problem shared by other countries as well. Wall, Andrus, and Morrison (2014) refer to a "theorypractice gap" in the nursing profession in Australia, proposing the use of simulations in academia. In Saudi Arabia, part of this gap can be attributed to the recent growth in nursing education facilities and the government's attempts to mitigate the significant shortage of nurses in the country.

Aldawsari and colleagues (2016) interviewed clinical teachers in Saudi Arabia to better understand their experience. They found that many teachers were hired without an official job 
description, which caused confusion at the organizational level. In addition, teachers described faulty communication concerning clinical placements, difficulties incorporating the students into the teaching hospital staff, and lack of acceptance of students by the nursing staff. These experiences were reflected in the current study.

The lack of preparation is not unique to Saudi Arabia, nor is it limited to the teaching staff. A qualitative study conducted in Iran revealed that nursing students were ill-prepared for their clinical placement; they reported problematic communications and emotional reactions and did not receive adequate attention from teaching staff (Jamshidi, Molazem, Sharif, Torabizadeh, \& Kalyani, 2016). In the current study, the participants commented on the lack of expertise among teaching staff, in addition to mentioning that most of their training was textbook-oriented rather than clinically oriented. Another issue related to gaps between teaching and practice raised by the participants was the language gap — while studies were conducted in English, the daily clinical work with patients is in Arabic, posing a challenge to the already difficult application of theory to practice.

Future nursing studies are needed to enhance nursing as a vital profession in Saudi Arabia. Primarily, competence and safe practice must be maintained. Financial support needs to be provided to encourage more Saudi students to pursue a career in nursing. It is imperative to promote the nursing profession by portraying a positive image of the profession. The media plays a vital role in promoting a favorable perception of nurses. Furthermore, more local nurses need to be recruited and retained in the workforce. Saudi nurses should care for Saudi patients because they share a common language, customs, and traditions. This can benefit the nursing education and health services outcomes, and ultimate, Saudi patients and their families. 
Limitations are present in this study. There was the lack of recent literature about nursing education in Saudi Arabia. Data collection was very challenging because the researcher was not able to meet the participants and used Skype to conduct the interviews. Some participants wanted to speak Arabic during the interview and that was challenging because the interviews were translated into English.

\section{Conclusion}

The current study revealed that the main challenges facing nursing education in Saudi Arabia include issues relating to nursing as a profession and its practice in the field, as well as nursing education and the lack of adequate field instruction and clinical skills offered by the staff and in the curriculum. These issues are not unique to Saudi Arabia; however, they may be more emphasized considering the sharp increase in nursing education programs and the immediate need for nurse educators. Considering the small pool of nurses and the need for new nurses, it is likely that these new educational programs accept nursing teachers who lack sufficient experience and expertise.

One of the benefits of teaching nursing in a classroom as opposed to online is the presence of a nurse as a teacher. The teacher, unlike a textbook, can add invaluable information gained in the field and clinical practice, as well as provide advice and answer students' questions. Moreover, teachers can serve as role models for the students, modeling a variety of skills. Therefore, it is essential to hire teachers who can provide these additional benefits. Furthermore, clinical training may benefit from improvements and added attention and emphasis, to mitigate teachers' lack of clinical experience in class. If clinical placements are managed correctly, they can augment and facilitate the learning of crucial clinical skills, as well as build students' confidence and expertise, better equipping them for their clinical practice. 


\section{Declarations}

\section{Acknowledgements}

The authors are thankful to the Deanship of Scientific Research, College of Nursing Research

Center at King Saud University for supporting this research.

\section{Conflicts of interest}

The authors declare no conflicts of interest.

\section{Author contributions:}

Study design: MA

Data collection: MA

Data analysis: RA and reviewed by MA

Discussion section: RA

Study supervision: MA

Manuscript writing: EA, SA, AA, RA

Critical revisions for important intellectual content: MA, RA, AA 


\section{References}

Aboshaiqah, A. (2016). Strategies to address the nursing shortage in Saudi Arabia. International Nursing Review, 63, 499-505. doi: 10.1111/inr.12271

Aboul-Enein, F. H. (2002). Personal contemporary observations of nursing care in Saudi Arabia. International Journal of Nursing Practice, 8, 228-230. doi: 10.1046/j.1440172X.2002.00370.X

Alboliteeh, M. (2015). Choosing to become a nurse in Saudi Arabia and the lived experience of new graduates: A mixed methods study. Unpublished doctoral dissertation, University of Adelaide, Adelaide, Australia.

Aldawsari, A. N., Babenko-Mould, Y., \& Andrusyszyn, M. A. (2016). Transitioning from nursing student to clinical teacher in Saudi Arabia. Journal of Nursing Education and Practice, 6, 76. doi: 10.5430/jnep.v6n2p76

Al-Hazmi, A., \& Windsor, C. A. (2013). The role of nurse educators in student clinical education in Saudi Arabia. Annual Worldwide Nursing Conference (WNC 2013), Global Science and Technology Forum, Singapore, pp. 1-10.

Al-Kandari, F. H., \& Lew, I. (2005). Kuwaiti high school students' perceptions of nursing as a profession: Implications for nursing education and practice. Journal of Nursing Education, 44, 533-540. doi: 10.1016/j.nedt.2017.02.008

Almalki, M., FitzGerald, G., \& Clark, M. (2011). The nursing profession in Saudi Arabia: An overview. International Nursing Review, 58, 1-8. doi: 10.1111/j.14667657.2011.00890.x 
Al-Omar, B. A. (2004). Knowledge, attitudes and intention of high school students towards the nursing profession in Riyadh city, Saudi Arabia. Saudi Medical Journal, 25, 150-155. PMID: 14968208

Braun, V., \& Clarke, V. (2006). Using thematic analysis in psychology. Qualitative Research in Psychology, 3(2), 77-101. https://doi.org/10.1191/1478088706qp063oa

Chan, Z. C. (2013). A systematic review of creative thinking/creativity in nursing education. Nurse Education Today, 33, 1382-1387. doi: 10.1016/j.nedt.2012.09.005

El-Sanabary, N. (2003). Women and the nursing profession in Saudi Arabia. In N. H. Bryant (Ed.), Women in nursing in Islamic societies. Karachi, Pakistan: Oxford University Press.

Foronda, C., Gattamorta, K., Snowden, K., \& Bauman, E. B. (2014). Use of virtual clinical simulation to improve communication skills of baccalaureate nursing students: A pilot study. Nurse Education Today, 34, e53-e57. doi: 10.1016/j.nedt.2013.10.007

Gazzaz, L. A. (2009). Saudi nurses' perceptions of nursing as an occupational choice: A qualitative interview study. Unpublished doctoral dissertation, University of Nottingham, Nottingham, UK.

Guest, G., MacQueen, K. M., \& Namey, E. E. (2011). Applied thematic analysis. Thousand Oaks, CA: SAGE Publications Ltd.

Hoeve, Y. T., Jansen, G., \& Roodbol, P. (2014). The nursing profession: Public image, selfconcept and professional identity. A discussion paper. Journal of Advanced Nursing, 70, 295-309. doi: 10.1111/jan.12177

Jamshidi, N., Molazem, Z., Sharif, F., Torabizadeh, C., \& Najafi Kalyani, M. (2016). The challenges of nursing students in the clinical learning environment: A qualitative study. The Scientific World Journal. doi: 10.1155/2016/1846178 
Kim, H., Sefcik, J. S., \& Bradway, C. (2017). Characteristics of Qualitative Descriptive Studies: A Systematic Review. Research in Nursing and Health, 40(1), 23-42. https://doi.org/10.1002/nur.21768

Lincoln, Y. S., \& Guba, E. G. (1985). Naturalistics inquiry. Beverly Hills: Sage Publications Inc. Mahran, S. M. A., \& Al Nagshabandi, E. (2012). Impact of perceived public image on turnover intention of female students from joining to nursing profession at King Abdul-Aziz University, Kingdom Saudi Arabia. Journal of Nursing and Health Science, 1, 19-28. doi: 10.9790/1959-0111928

Melnyk, B. M., Gallagher-Ford, L., Long, L. E., \& Fineout-Overholt, E. (2014). The establishment of evidence-based practice competencies for practicing registered nurses and advanced practice nurses in real-world clinical settings: Proficiencies to improve healthcare quality, reliability, patient outcomes, and costs. Worldviews on EvidenceBased Nursing, 11, 5-15. doi: 10.1111/wvn.12021

Mutair, A. (2015). Clinical nursing teaching in Saudi Arabia challenges and suggested solutions. Journal of Nursing \& Care, 4, 2167-1168. doi: 10.4172/2167-1168.S1-007

Qu, S. Q., \& Dumay, J. (2011). The qualitative research interview. Qualitative Research in Accounting and Management, 8(3), 238-264. doi:10.1108/11766091111162070

Rezaei-Adaryani, M., Salsali, M., \& Mohammadi, E. (2012). Nursing image: An evolutionary concept analysis. Contemporary Nurse, 43, 81-89. doi: 10.5172/conu.2012.43.1.81

Saifan, A., AbuRuz, M. E., \& Masa'deh, R. (2015). Theory practice gaps in nursing education: A qualitative perspective. Journal of Social Sciences, 11, 20-29. doi:

$10.3844 /$ jssp.2015.20.29 
Sharif, F., \& Masoumi, S. (2005). A qualitative study of nursing student experiences of clinical practice. BMC Nursing, 4, 6. doi: 10.1186/1472-6955-4-6

Wall, P., Andrus, P., \& Morrison, P. (2014). Bridging the theory practice gap through clinical simulations in a nursing under-graduate degree program in Australia. International Journal of Learning, Teaching and Educational Research, 8, 127-135. 